\title{
Formação continuada: contribuições para o desenvolvimento profissional dos professores
}

\author{
Continuous development: some contributions \\ for teachers' development
}

\section{Joana Paulin Romanowski[ ${ }^{[a]}$, Pura Lúcia Oliver Martins ${ }^{[b]}$}

[a] Doutora em Educação pela Universidade de São Paulo (USP), professora titular da Pontifícia Universidade Católica do Paraná (PUCPR), Curitiba, PR - Brasil, e-mail: joana. romanowski@pucpr.br

[b] Doutora em Educação pela Universidade de São Paulo (USP), professora do Programa de Pós-Graduação em Educação da Pontifícia Universidade Católica do Paraná (PUCPR), Curitiba, PR - Brasil, e-mail: pura.oliver@pucpr.br

\section{Resumo}

O objetivo deste trabalho é analisar as contribuições da formação continuada para odesenvolvimento profissional dos professores. Toma como referência pesquisas realizadas no período de 2005 a 2008, pelo grupo de pesquisa Práxis educativa: dimensões e processos. O ponto de partida para o estudo são depoimentos de professores sobre o processo de formação continuada, e as análises apoiam-se na sistematização de Santos (2005) que estabelece, em termos didáticos, diferentes 
níveis de conhecimento, do descritivo ao compreensivo, passando pelo nível explicativo. Destaca o contexto em que se institui a formação continuada no Brasil e as atuais exigências para o desempenho profissional do professor.

Palavras-chave: Formação continuada. Desenvolvimento profissional. Formação de professores.

\section{Abstract}

This paper has as main goal to analyse some contributions for continuous development for teachers' professional development. Some investigations taken from 2005 to 2008 are reference and the base of the study. They were performed through the research group Education Praxis: dimensions and processes. Teacher's testimonials about the continuous development process are the starting point for the investigation, and the analysis are focused on Santos (2005) systematization, establishing in teaching words different knowledge levels. From the descriptive to the understanding level, also passing through the explanatory one. This paper calls attention for the context in which the Continuous Development takes part in Brazil as well as the demands for the Professional Teachers' Development.

Keywords: Continuous development. Professional development. Formation of professors.

\section{Introdução}

Este texto focaliza a relação entre formação continuada e desenvolvimento profissional dos professores, realizando uma análise de programas de formação a partir de relatos indiciários ${ }^{1}$ de professores registrados por meio de pesquisas realizadas em escolas de educação básica da rede pública

\footnotetext{
${ }^{1} \mathrm{O}$ Relatos indiciários referem-se a registros que expressam diferentes práticas de formação continuada no contexto escolar. O termo "indiciário" originalmente foi utilizado por Monteiro (2000), em sua dissertação, na qual o autor buscou revelar a postura político-ideológica de professoras alfabetizadoras de jovens e adultos, apresentando a expressão incidentes indicirios.
}

Rev. Diálogo Educ., Curitiba, v. 10, n. 30, p. 285-300, maio/ago. 2010 
e privada. Constitui questão norteadora examinar se atualmente a formação continuada favorece o desenvolvimento profissional dos professores, contribuindo para uma consequente melhoria da prática pedagógica.

Considera-se desenvolvimento profissional "um processo através do qual os trabalhadores melhoram o seu estatuto, elevam seus rendimentos e aumentam o seu poder/autonomia" (NÓVOA, 1992, p. 2). Isso pressupõe que o estatuto profissional constitui-se historicamente, concomitantemente favorecido por condições institucionais, pelo coletivo da categoria e pela valorização social, quer dizer, o desenvolvimento profissional dos professores se consolida com a melhoria do estatuto da escola e do ensino (MARCELO, 1999; RAMALHO; NUÑEZ; GAUTHIER, 2003).

Entre as condições de profissionalização está uma sólida formação aliada à conquista da autonomia individual e coletiva. Deste modo, a formação continuada no Brasil constitui um dos elementos de desenvolvimento profissional dos professores, pois complementa a formação inicial e constitui condição de acesso para níveis mais elevados na carreira docente.

A formação continuada de professores, tema deste texto, será analisada apoiada na sistematização de Santos (2005) que estabelece, em termos didáticos, diferentes níveis de conhecimento. Do descritivo ao compreensivo, passando pelo nível explicativo, organizamos o texto partindo de relatos indiciários de professores; em seguida, as práticas de formação continuada historicamente situadas, finalizando com as análises decorrentes quanto à contribuição dessas práticas no desenvolvimento profissional dos professores.

Partimos do pressuposto básico de que os problemas que afetam a formação dos professores, sobretudo a desarticulação entre a formação e a prática docente, expressam a nova configuração da organização do trabalho sob critérios de produtividade e excelência, expressando uma regulação que, embora dirigida à promoção da educação para todos, encontra-se fortemente ancorada no mercado e controle do trabalho, conforme apontam Freitas (1995) e Oliveira (2007). Freitas (1995) afirma a exigência de que a educação deve adequar-se à necessidade de promover uma formação para atender novos padrões de competitividade internacional no novo redimensionamento econômico. Os professores estarão envolvidos duplamente no contexto dessas exigências: na promoção de um novo modelo de educação e na categoria de trabalhadores. Para analisar essas questões, é fundamental contextualizar historicamente a relação formação continuada e profissionalização docente. 
Assim, para encaminhar a reflexão sobre as contribuições da formação continuada para o desenvolvimento profissional docente, tomamos como eixo epistemológico a concepção de teoria como expressão da prática, entendendo que as relações sociais básicas do modo de produção em diferentes momentos históricos se manifestam no interior das instituições educacionais, incidindo sobre as formas e práticas dos processos de formação docente. Nas palavras de Santos (1992, p. 124),

a compreensão da realidade social decorre não da assimilação resultante da transmissão de 'bons conteúdos', mas sim da prática sobre essa realidade social. É a teoria que é a expressão da prática: e são tantas práticas... É este o papel do conhecimento; ele é meio, não se constitui em objetivo em si mesmo.

Cabe destacar que a formação continuada efetiva-se desde longa data no Brasil, pois o sistema de ensino foi instituído antes que houvesse professores preparados para exercer a docência. Professores leigos eram indicados para exercer a docência e durante o exercício adquiririam prática profissional. Com efeito, a formação continuada assumiu o caráter de suprimento, como aponta Gatti (2007), em que o sistema realiza a formação necessária dos professores durante o exercício profissional, complementando uma formação inicial deficiente e/ou inexistente. Desse modo, a formação continuada é constituinte do próprio sistema escolar, mas sem que uma política para essa formação tenha sido definida.

\section{A institucionalização da formação continuada}

Os relatórios dos inspetores escolares, no período imperial, já denunciavam a falta de formação dos professores. Diante deste quadro de precariedade, algumas medidas foram tomadas: a realização de exames de habilitação para os vocacionados para o magistério, a existência de professores adjuntos atuando com mestres-escolas, a criação de cursos normais, e nestes a classe para professores não diplomados e que atuavam nas salas de aula, além da formação dos que iriam ingressar nos sistemas escolares (WACHOWICZ, 1984).

Mesmo com a criação das escolas normais, o número de professores devidamente formados era insuficiente para atender à demanda das escolas, 
o que só consolidou o modelo de formação continuada de suprimento, isto é, a oferta de formação em serviço. Na década de 1940, essa formação é impulsionada por várias iniciativas, desde a criação de órgãos e programas presenciais e a distância. Entre esses programas, cabe citaro Pabaee, Programa de Assistência Brasileiro-Americana ao Ensino Elementar, que consistia na "assistência/assessoria" do governo americano à educação no Brasil. Foi iniciado em 1942 e constituiu-se, basicamente, de treinamento nos EUA de professores líderes para a introdução de novas metodologias e técnicas de ensino, além de fornecimento de materiais didático-pedagógicos. Os objetivos desse programa estavam centrados, inicialmente, na formação dos professores de Escolas Normais Oficiais, que seriam os responsáveis pelo papel de multiplicar para o conjunto dos demais professores as inovações necessárias a serem introduzidas na prática pedagógica.

O Instituto Nacional de Estudos Pedagógicos (INEP), embora tenha sido criado em 1937 para realizar a pesquisa sobre a educação brasileira por meio de censo escolar para orientar a formulação de políticas públicas, também desenvolveu cursos de formação continuada de professores em várias regiões do país.

Cabe destacar que a formação dos professores situa-se no contexto de tendências da prática pedagógica. Nesse período, o escolanovismo é dominante e insere-se na formação docente. A ênfase da formação considerava práticas de laboratório educativo, isto é, o professor experimentava as propostas indicadas nos estudos teóricos e com base nesta experiência mudaria sua prática pedagógica. Nesse processo, a teoria constitui-se guia da prática. Por exemplo, o movimento de criação das escolas de aplicação, referência desta tendência, instaladas como anexas às faculdades e institutos de educação, nas quais os alunos do curso normal e das licenciaturas deveriam desenvolver experiências de ensino com base nas teorias estudadas (BEISIEGEL, 2003).

A partir do final da década de 1960, a formação continuada passa a constituir-se complementação profissional como reciclagem e treinamento, sob a forma de cursos de curta duração e palestras. A ênfase dos conteúdos desses cursos é a organização do planejamento do ensino, dos materiais instrucionais e da avaliação. Os professores são treinados para elaborar objetivos instrucionais que permitam controlar a aprendizagem dos alunos e organizar mapas com percentuais de comportamentos atingidos, bem como elaborar questões de testes de itens tecnicamente corretos. 
Nessa década, a concepção tecnicista perpassa a organização dos sistemas de ensino e das práticas pedagógicas, inclusive por força legal. O controle instalado com divisão do trabalho na escola impõe aos professores uma organização técnica do ensino com a consequente desvalorização do trabalho do professor, restrito à execução do planejamento. Portanto, a formação continuada restringe-se à aplicação na prática dos modelos preconizados, visando à organização do ensino eficiente e eficaz. No entanto, a ascensão na carreira se realiza por tempo de serviço e por mérito. O mérito por bons serviços prestados é indicado pelo chefe imediato. Um segundo modo de ascensão profissional constitui-se pela nomeação a cargos de diretor de escola, inspetor de ensino e outras funções administrativas, nas quais gratificações são acrescidas à carreira. Essa nomeação assume o caráter de reconhecimento e valorização profissional.

No final da década de 1970, a formação continuada assume a forma de aperfeiçoamento, atualização, capacitação, educação permanente e educação continuada. A ênfase dos programas de formação dos professores são os conteúdos de ensino na perspectiva crítica. Esses conteúdos são trabalhados em cursos de curta duração, palestras e seminários com ênfase na transmissão de conhecimentos aos professores, em que se adota o mesmo formato dos cursos de formação inicial, ainda que as concepções críticas constituam a tendência da prática pedagógica. Com efeito, é a partir dos anos 80 que a ênfase das análises em educação direciona-se para questões sobre a organização pedagógica e dos currículos escolares, sob os efeitos das teorias reprodutivistas da década anterior.

Destaca-se que nesse período, a formação continuada passa a ser considerada na carreira docente. A promoção dos professores realiza-se considerando a titulação, os cursos de nível superior de graduação concluídos após o ingresso nos sistemas escolares. O acesso a níveis mais elevados na carreira profissional inclui avaliação por contagem de pontos do número de cursos de formação continuada realizado pelo professor. O tempo de serviço é considerado insuficiente para a progressão profissional. A avaliação do desempenho profissional é sistemática, o chefe imediato não indica por mérito, mas faz uma avaliação de desempenho definida e registrada em documentos escritos, iniciando o controle do trabalho docente.

Uma nova tendência configura-se nos estudos sociológicos a partir dos anos de 1990, ocorre a ruptura da perspectiva de análise das estruturas 
educacionais, gradativamente a análise passa para os sujeitos atores, análise sobre os professores e suas práticas, segundo Paixão (1993).

A formação continuada de professores incorpora essa nova tendência, trata-se de uma perspectiva de formação que se caracteriza por considerar o professor como sujeito da sua própria prática. A esse respeito, Lelis (2001, p. 53) destaca que a:

ênfase na relação entre dimensão pessoal, profissional e organizacional da profissão docente (NÓVOA, 1992), seja pela via de que o saber docente provém de várias fontes e de que a prática cotidiana faz brotar o "saber da experiência" (TARDIF; LESSARD; LAHAYE, 1991), ou ainda do habitus profissional como "gramática geradora de práticas" (PERRENOUD, 1993), a fecundidade dessas propostas está, de um lado, na forte crítica à razão instrumental e, de outro lado, na valorização da prática individual e coletiva como lugar de aprendizagem dos conhecimentos necessários à existência pessoal, social e profissional (DOMINICÉ, 1990).

Essa perspectiva aponta para várias implicações na vida escolar e na formação continuada dos professores, na medida em que dirige no interior da escola a atenção para a promoção de experiências que contemplem componentes formativos articulados ao cotidiano escolar do professor, conforme Sztajn, Bonamino e Franco (2003).

Neste sentido, a formação de professores implica na existência de um novo formato para favorecer processos coletivos de reflexão einteração; a oferta de espaços e tempos para os professores dentro da própria escola; a criação de sistemas de incentivo à sua socialização; a consideração das necessidades dos professores e dos problemas do seu dia a dia (SZTAJN, et al., 2003).

A análise desta atual perspectiva de formação será abordada em seguida, a partir dos depoimentos dos docentes obtidos nas investigações realizadas pelo grupo de pesquisa. Conforme está expresso no início do texto, a abordagem considera oprimeiro nívelo da descrição para onívelde explicaçãoe de compreensão da relação entre formação continuada e desenvolvimento profissional.

\section{Cenário atual da formação continuada: relatos indiciários}

Em pesquisas realizadas destacam-se depoimentos de professores constituindo indícios para a descrição e análise do cenário atual da formação 
continuada. Os dois primeiros relatos foram extraídos em consultas aos registros de investigações realizados por membros do grupo de pesquisa. Os relatos 3 e 4 foram obtidos com mestrandos participantes da pesquisa durante 2007, o último é o relato de uma aluna do curso noturno de graduação em Pedagogia, e que atua na educação infantil.

\section{Relato 1}

As reuniões, encontros de formação continuada promovidos pelas redes de ensino privada e pública, segundo os professores e coordenadores pedagógicos apontam:

Na verdade não há um programa de formação continuada, são realizadas reuniões, conforme a necessidade são estudados, refletidos e debatidos os assuntos. Não é aceita a certificação desses cursos para avanços profissionais (os cursos realizados pela escola); muitas vezes os assuntos já estão saturados; as propostas dos programas nem sempre condizem com a realidade; a oferta de cursos é muito restrita, principalmente os especificos da minha área.

\section{Relato 2}

As reflexões realizadas individualmente pelos professores sobre sua prática pedagógica:

Ser capaz de refletir sobre sua prática pedagógica e não ficar chocado quando receber uma avaliação ruim, entender que talvez. tenha alguma relação com a forma que ele está trabalhando, com sua vida pessoal que não está muito bem, descontente com a instituição ou na sua relação com os alunos. Acredito que o ponto principal da reflexão é fazer com o professor seja reflexivo o suficiente para entender que ele também erra, e nem sempre aborda um conteúdo como deveria ser focado.

\section{Relato 3}

Avaliação sobre os cursos de formação continuada realizados na rede pública de ensino:

Se a intenção da formação continuada é proporcionar a reflexão sobre a ação profissional, posso afirmar que em vários momentos de formação pelos quais passei me fizeram querer voltar para a escola para colocar em prática 
aquilo que havia sido discutido e refletido. Não como uma aplicação de uma receita aprendida, mas como resultado de uma reflexão sobre a prática que já vinha desenvolvendo com os alunos em sala. Era uma forma de se distanciar do trabalho pedagógico como estratégia para ter espaço para enxergá-lo de outros ângulos e com outros olhares.

\section{Relato 4}

Este relato também é uma avaliação sobre cursos e palestras de formação continuada ofertados em uma rede de ensino confessional:

As capacitações que eram oferecidas pela instituição não trabalhavam a necessidade que tinhamos como professores, mas apenas abordavam as necessidades que a direção achava ser interessante para o desenvolvimento geral da escola. A cada ano eram trazidas ideias novas, não para a prática docente, mas para tornar-nos, segundo a administração, mais "atualizados" nas tendências educacionais e que, na prática do ensino ou na formação do professor diretamente nada era abordado.

\section{Relato 5}

Registro do relato de uma aluna de graduação que atua na rede privada de ensino:

O diretor convoca para curso em janeiro, antes do início das aulas. Anuncia que o curso trará novidades. As férias são encurtadas e o curso é o mesmo de sempre, mas a escola precisa dizer para os pais, colocar no folder que os professores são atualizados, que participam de cursos.

\section{O que dizem esses relatos?}

O primeiro relato refere-se a uma pesquisa realizada em escolas da rede pública e privada, com professores do ensino médio, realizada por Gomes (2006). Essa pesquisa focaliza o espaço da escola na realização de formação continuada para o desenvolvimento profissional e a consequente melhoria da prática pedagógica. Os colégios pesquisados são instituições de ensino consideradas boas escolas, bem equipadas, que trabalham com alunos oriundos de camadas com melhores condições econômicas, escolarização e cultural. 
Os resultados obtidos apontam que os professores possuem carga elevada de trabalho, com aulas ministradas em diferentes colégios, e não dispõem de tempo para a realização de grupos de estudo, leituras e ampliação cultural. As escolas promovem poucas oportunidades de cursos, reuniões e outras formas de formação continuada. As que são promovidas apresentam uma contribuição restrita na atualização dos professores em relação aos conhecimentos específicos; a maioria delas versa sobre questões pedagógicas genéricas e não diretamente relacionadas a problemas do ensino médio. Um dos diretores afirma que ele próprio não participa dos cursos, apenas estimula os professores a participarem.

O segundo relato refere-se às contribuições da reflexão sobre a prática realizada por professores para possibilitar mudanças nesta prática, feita por Souza (2005). Foram entrevistados professores do ensino superior de uma instituição privada. Os resultados expressam que todos os professores refletem antes, durante e com mais intensidade após as suas aulas. Ao fazerem a reflexão, encontram novas alternativas para as aulas. Nesta pesquisa evidencia-se que o objeto da reflexão sofre mudanças no decorrer do tempo do exercício profissional, professores iniciantes tendem a preocupar-se mais com os conteúdos e os procedimentos de ensino e os mais experientes, com a aprendizagem de seus alunos, como expressa Souza (2005).

No entanto, o processo de reflexão não origina uma sistematização da prática, constitui-se mais como processo voluntário, de improvisação, sem registro e sem reconhecimento institucional. A avaliação do desempenho é realizada pelo coordenador com base nas suas impressões sem que tenha assistido a uma só aula do professor; semestralmente pelos alunos, que atribuem nota ao desempenho didático do professor. Os resultados obtidos nessa avaliação são indicativos para o acompanhamento e controle do professor. Em alguns casos, itens com menor nota constituem tema de alguma palestra a ser proferida no início do período letivo, cumprindo as exigências de desenvolvimento de formação continuada.

O terceiro e quarto relato referem-se à avaliação de experiências de formação continuada realizada por grupo de mestrandos em educação, expressos em registros escritos. O primeiro reporta-se a uma rede de ensino público municipal que desenvolve sistematicamente cursos, palestras, encontros, grupos de estudo, projetos de pesquisa ação, orientações, reuniões e eventos para o conjunto de professores desde a criação da rede de ensino. 
Cabe destacar que há mais de 20 anos a carreira do professor está vinculada à participação em programas de formação continuada e avaliação de desempenho. Esta avaliação é realizada pela equipe pedagógica de cada uma das escolas. No entanto, nos últimos anos o acesso a níveis mais elevados da carreira está condicionado à existência de vagas nesses níveis. Além de obter os pontos exigidos, o professor se submete às provas e exames para concorrer às vagas, isto é, o desenvolvimento profissional depende de certificação. Certificação aqui entendida como avaliação de competência.

O relato 4 também se refere à avaliação de experiência realizada em formação continuada e focaliza uma rede confessional de ensino. Verifica-se que neste relato a formação continuada não se articula aos problemas da prática dos professores. Neste caso, os cursos parecem cumprir uma exigência de oferta institucional. Igualmente, o relato 5 expressa o depoimento de uma professora da educação infantil que se vê na obrigatoriedade de realizar o curso por exigência institucional.

O conjunto desses relatos indiciários expressa práticas de formação continuada realizadas na escola e nas redes de ensino básico. São indicativos obtidos em pesquisas que têm por foco o tema da formação continuada. A análise pretendida após a descrição é de segundo nível de explicação, como expressa Santos (2005). Os pontos a serem destacados reportam-se à relação entre a formação continuada e o desenvolvimento profissional e a consequente melhoria da prática pedagógica.

Ainda nesse nível de descrição, os professores ressaltam como dificuldade para participar dos programas de formação continuada oferecidos pelas escolas, a elevada carga de trabalho, como aponta Gomes (2006, p. 67); correm de uma escola para outra, em espaços de tempo mínimos. Atrelado a esta dificuldade, o desestímulo em participar deve-se a serem atividades formadoras desinteressantes por não abordarem questões de interesse dos professores.

\section{Relação entre formação continuada e desenvolvimento profissional}

$\mathrm{Na}$ atualidade, a formação continuada dos professores apresenta-se diversificada tanto em forma como em conteúdo. Milhares de professores ainda não possuem formação superior, e isso exige a 
oferta de cursos de graduação presencial ou a distância aos professores em serviço. $\mathrm{Na}$ maioria dos casos, esses cursos são realizados pelos professores para além de sua jornada de trabalho nas escolas.

Para os professores já titulados, em todos os níveis de ensino, a formação continuada assume diferentes perspectivas: suprimento, atualização, treinamento, aprofundamento, pesquisa. Suprimento direcionado para formação complementarà inicial, considerada, na maioria das vezes, precária. Marin (1996) e Martins (2009) denunciavam as dificuldades históricas de formar bem os professores, que exige a continuidade de cursos ao longo da carreira docente.

Além disso, os sistemas de ensino, por exigência legal inclusa nas avaliações de credenciamento institucional, por necessidade do atual contexto sócio-histórico, por exigências da competividade de mercado, e mesmo por compromisso com a melhoria do estatuto da formação docente e a consequente melhoria da prática pedagógica, ofertam aos seus professores palestras e cursos, no início e durante o ano letivo.

No entanto, vinculado aos propósitos com que são realizadas essas ofertas, o conteúdo da formação continuada inclui desde cursos de autoajuda, qualidade de vida, relação afetiva com os alunos, como usar as novas tecnologias no ensino, à análise da prática pedagógica ${ }^{2}$. Deste modo, o leque de ofertas de cursos e palestras é realizado por empresas especializadas em organização de eventos; promoção pelo próprio sistema escolar por meio de setor responsável por essa formação; participação das universidades e mesmo de pesquisadores que desenvolvem projetos de pesquisa e estudo em escolas, conforme se depreende dos relatos indiciários e das pesquisas consultadas.

Cabe destacar que, em algumas escolas, há o desenvolvimento de grupos de estudo e de trabalho em processo permanente de formação dos professores, mas, como afirma Gatti (2007), ainda não há uma política de formação continuada. Assim, realizamos uma primeira análise de implicações, considerando a relação formação continuada e desenvolvimento profissional. Para tal, o estudo considera referenciais da área no esforço de inferir das práticas de formação e indicações explicativas.

\footnotetext{
${ }^{2}$ Pesquisa realizada por Romanowski, Martins e Wachowicz (2005) sobre os temas de monografias de professores da educação básica que apontam para esta diversidade, principalmente referente a dificuldades de aprendizagem dos alunos e relacionadas à afetividade.
}

Rev. Diálogo Educ., Curitiba, v. 10, n. 30, p. 285-300, maio/ago. 2010 
A profissão do professor nos tempos atuais está marcada por intensificação de quantificação de tarefas e de maior complexidade. Hargreaves (1994), ao discorrer sobre o trabalho docente, expressa o "profissionalismo alargado". Alerta este autor para a redução do tempo com a intensificação do processo de trabalho, o que acarreta falta de tempo para alimentar-se e para aperfeiçoamento, criando uma sobrecarga crônica e persistente. Tudo isso provoca redução na qualidade do ensino, especialmente, no caso dos professores, redução do tempo de preparação, condição fundamental para um bom ensino (HARGREAVES, 1994, p. 134-137).

Sobre o alargamento, o levantamento realizado por Fanfani (2005, p. 85) sinaliza para um número elevado de professores que trabalha em duas ou mais instituições e, mais do isso, as inúmeras atividades como a coordenação de atividades com outros professores, a participação em projetos institucionais e de articulação com a comunidade, a atenção personalizada aos alunos. Essa crescente ampliação de atividades fragmenta o trabalho e não contribui para a identidade do professor com as instituições em que atua.

Além disso, conforme aponta Oliveira (2007), o novo modo de organização escolar em que a escola passa a assumir responsabilidades pela definição dos currículos, de gestão e de relação com a comunidade, amplia a demanda de atividades e responsabilidades do professor. Paradoxalmente, a autonomia e a flexibilidade trazem aos professores uma carga maior de responsabilidade pelo sucesso e fracasso da escola, elencaimplicações das atuais mudanças na escola brasileira, com a expansão dos níveis de escolarização e de acesso à população que estava excluída da escola, desde a necessidade de assegurar o sucesso da escolarização ao conjunto dos alunos, a reorganização das práticas pedagógicas, do currículo, inclusive a convivência com a violência.

Para Nóvoa (2007,p. 2), as atuais exigências em torno da escola ampliam o trabalho docente, paradoxalmente, ao atribuir-se mais responsabilidade aos professores, os quais são enfraquecidos profissionalmente. Nas palavras do autor:

Há um paradoxo entre o excesso das missões da escola, o excesso de pedidos que a sociedade nos faz e, ao mesmo tempo, uma cada vez maior fragilidade do estatuto docente. Os professores têm perdido prestígio, a profissão docente é mais frágil hoje do que era há alguns anos. Eis um enorme paradoxo. Como é possível a escola nos pedir tantas coisas, atribuir-nos tantas missões e, ao mesmo tempo, fragilizar nosso estatuto profissional? 
Um segundo paradoxo mencionado pelo autor refere-se à atual valorização do conhecimento e o crescente desprestígio dos professores. Confere-se para a escola inúmeras atribuições, desde a promoção do desenvolvimento dos alunos, a inserção de novos conhecimentos e não raro a indicação da participação da escola na promoção do desenvolvimento econômico. Por exemplo, aos sinais da degradação ambiental, imediatamente foram acrescidos conhecimentos sobre ecologia nos currículos escolares. Neste caso, o paradoxo está em considerar os professores considerados profissionais medíocres passíveis de participarem de inúmeros cursos para sua formação e atualização e a eles atribuir aquele conjunto de responsabilidades sobre a distribuição do conhecimento e de promoção social.

Já apontava Freitas (1995, p. 95) que o neotecnicismo tem como tentativa envolver o professor com o trabalho de reconstrução econômica, "nesse processo, tenta-se passar a idéia de que o professor deve ter autonomia, que a administração deve ser descentralizada, participativa, mas, no entanto, esse processo "democrático" deve servir a interesses centralizados e não aos interesses dos professores, alunos ou classes populares". Há um processo centralizado de controle com autonomia de execução local.

Cabe, ainda, salientar a permanente denúncia do fracasso da escola alardeada pelos resultados das avaliações nacionais. As médias obtidas pelos alunos, nos exames do SAEB, ENADE, e outras avaliações, são consideradas insuficientes. Não raro responsabiliza-se os professores por esses resultados.

Ao finalizarmos este artigo, considerando a pesquisa realizada sobre formação continuada e o atual contexto de ampliação e responsabilização no trabalho docente, verifica-se a tendência crescente de possibilidade de que a formação continuada é mais uma nova forma de regulação profissional do que rumo à promoção da profissionalização docente.

A profissionalização cumpre o alargamento com a atribuição de maiores tarefas aos professores, sem o correspondente estatuto de valorização profissional e prestígio social. Aliás, como alerta Hargreaves (1994), as qualidades próprias da pessoalidade do professor tornam-se exigências de desempenho profissional, para além do desempenho do profissional professor. 


\section{Referências}

BEISIEGEL, C. R. Origens da pesquisa educacional na USP. Educação e Pesquisa, v. 29, n. 2, p. 357-364, 2003.

DOMINICÉ, P. L'histoire de vie comme processus de formation. Paris: L'Harmattan, 1990.

FANFANI, E. T. La condicion docente: análisis comparado de la Argentina, Brasil, Perú y Uruguai. Buenos Aires: Siglo XXI, 2005.

FREITAS, L. C. Neotecnicismo e a formação do educador. In: ALVES, N. (Org.). Formação de professores: pensar e fazer. 3. ed. São Paulo: Cortez, 1995.

GATTI, B. A. Análise das políticas públicas para a formação continuada de professores no Brasil na última década. In: REUNIÃO ANUAL DA ANPEd, 30., 2007. Caxambu. Reunião de Trabalho... Caxambu: [s.n.], 2007. (GT 08 Formação de Professores, anotações da comunicação).

GOMES, C. C. A formação continuada de professores do ensino médio: a escola como espaço para o desenvolvimento profissional. 2006. 174 f. Dissertação (Mestrado) - Pontifícia Universidade Católica do Paraná, Curitiba, 2006.

HARGREAVES, A. Os professores em tempos de mudança: o trabalho e a cultura dos professores na idade pós-moderna. Lisboa: McGraw-Hill, 1994.

LELIS, I. A. Do ensino de conteúdos aos saberes do professor: mudança de idioma pedagógico? Educação \& Sociedade, v. 22, n. 74, p. 43-58, 2001.

MARCELO GARCIA, C. Formação de professores: para uma mudança educativa. Porto: Porto, 1999.

MARIN, A. J. Propondo um novo paradigma para formar professores a partir das dificuldades e necessidades históricas nessa área. In: REALI, A. M. M. R.; MIZUKAMI, M. G. N. Formação de professores: tendências atuais. São Carlos: EdUFSCar, 1996. p. 59-91.

MARTINS, P. L. O. A didática e as contradições da prática. 3. ed. Campinas, SP: Papirus, 2009.

NÓVOA, A. (Coord.). Os professores e sua formação. Lisboa: Dom Quixote, 1992. 
. Desafios do trabalho do professor no mundo contemporâneo. São Paulo, SNPRO-SP, 2007. Disponível em: < http://www.sinprosp.org.br/arquivos/ novoa/livreto_novoa.pdf>. Acesso em: 05 out. 2007.

OLIVEIRA, D. A. Política educacional e a re-estruturação do trabalho docente: reflexões sobre o contexto latino-americano. Educação \& Sociedade, v. 28, n. 99, p. 355-375, 2007.

PAIXÃO, L. P. A sala de aula como objeto de estudo da sociologia da educação nos Estados Unidos, Inglaterra e França. In: OLIVEIRA, M. R. N. S. Didática: ruptura, compromisso e pesquisa. Campinas, SP: Papirus, 1993. p. 15-33.

PERRENOUD, P. Práticas pedagógicas, profissão docente e formação: perspectivas sociológicas. 2. ed. Lisboa: Dom Quixote, 1997.

RAMALHO, B. L.; NUÑEZ, I. B.; GAUTHIER, C. Formar o professor, profissionalizar o ensino: perspectivas e desafios. Porto Alegre: Sulina, 2003.

ROMANOWSKI, J. P.; MARTINS, P. L. O.; WACHOWICZ, L. A. Saberes docentes e os determinantes da prática social. Revista Diálogo Educacional, v. 5, n. 16, p. 11-24, 2005.

SANTOS, O. J. Pedagogia dos conflitos sociais. Campinas, SP: Papirus, 1992.

SOUZA, G. M. R. de. Professor reflexivo no ensino superior: intervenção na prática pedagógica. 2005. 148 f. Dissertação (Mestrado em Educação) - Pontifícia Universidade Católica do Paraná, Curitiba, 2005.

SZTAJN, P.; BONAMINO, A.; FRANCO, C. Formação docente nos surveys de avaliação educacional. Cadernos de Pesquisa, n. 118, p. 11-39, 2003.

WACHOWICZ, L. A. Relação professor-Estado no Paraná tradicional. São Paulo: Cortez, 1984.

Recebido: 15/05/2009

Received: 05/15/2009

Aprovado: 19/06/2009

Approved: 06/19/2009 